\title{
Sade e Schopenhauer: matéria e metafísica
}

\section{Sade and Schopenhauer: Matter and metaphysics}

\author{
Eduardo R. da Fonseca \\ Docente e pesquisador da PUC-PR \\ E-mail: eduardorfonseca@uol.com.br
}

Resumo: Sade e Schopenhauer são filósofos que pensaram a matéria ao mesmo tempo em que descartaram o criacionismo. Schopenhauer pensa a matéria e suas formas no interior de sua metafísica da vontade, enquanto Sade é um materialista propriamente dito, que parte da física e leva a sua concepção de matéria às últimas consequências. Em ambos os autores, o que é inerente ao mundo material é o conflito e o desgaste, o horror e a banalidade do mal, bem como a indiferença cósmica inerente aos fenômenos que constituem o mundo. O presente artigo analisa as peculiaridades do materialismo em ambos os autores e interpreta a concepção de Sade à luz do ponto de vista schopenhaueriano.

Palavras-chave: Materialismo; Morte; Sexualidade; Maldade; Indiferença.

Abstract: Sade and Schopenhauer are philosophers who thought about matter while discarding creationism. Schopenhauer thinks matter and its forms within his metaphysics of the will, while Sade is a materialist himself who starts from physics and takes his conception of matter to the ultimate consequences. In both writers, what is inherent in the material world is the conflict and weariness, the horror and banality of evil, as well as the cosmic indifference inherent in the phenomena that constitute the world. The present article analyzes the peculiarities of materialism in both authors and interprets the conception of Sade under the light of the Schopenhauerian point of view.

Keywords: Materialism; Death; Sexuality; Wickedness; Indifference.

"A matéria é a própria vontade" (Arthur Schopenhauer)

A intenção deste texto é pensar os problemas inerentes ao materialismo no contexto da filosofia de Schopenhauer, utilizando como objeto de reflexão os escritos de Sade e aquilo que podemos pensar eventualmente como as consequências de sua filosofia no contexto da existência, especialmente as questões ligadas à sexualidade, à política e à moralidade. Não é algo óbvio estabelecer qualquer aproximação entre o pensamento desses autores, mas podemos imaginar, mediante a leitura de ambos, o que Schopenhauer poderia pensar acerca da filosofia sadiana, tendo ao fundo o contexto do materialismo francês bem conhecido e discutido pelo autor alemão no âmbito de um debate sistemático 
maior envolvendo o idealismo e o ceticismo. Ao mesmo tempo em que reconhece o materialismo como o mais consequente dentre os três sistemas de pensamento, Schopenhauer faz, no entanto, uma crítica direta aos seus fundamentos.

É nesse contexto que a reflexão sobre Sade será feita aqui, considerando também que as filosofias de ambos se colocam abertamente em uma postura de combate contra $o$ dogmatismo. Esse antidogmatismo aparece no contexto do materialismo ao qual nos referimos. Trata-se do baixo contínuo sobre o qual se constroem tanto as harmonias quanto as melodias inerentes aos seus diferentes pensamentos, que são evocados juntos devido à contribuição que a análise schopenhaueriana do materialismo propicia do ponto de vista do pensamento acerca da vida e da animalidade, ainda que o pensamento acerca da moralidade adquira, em seu caso, uma peculiaridade que faz dele um filósofo muito diferente do nosso Marquês. As considerações morais de Schopenhauer receberiam, provavelmente, um olhar de escárnio de Sade, pelo seu acento na compaixão como contraponto justamente ao egoísmo e à crueldade inerentes ao impulso cego que representa o querer-viver.

\section{Visão geral do materialismo na obra de Schopenhauer}

As considerações de Schopenhauer acerca do materialismo filosófico podem ser encontradas no parágrafo 7 de "O Mundo como vontade e representação" (1819), e estão expostas também em outros textos, especialmente nos "Complementos" (Ergänzungen) (1844) à obra magna de Schopenhauer. Em 1819, o filósofo sugeriu que tanto o materialismo como o idealismo, caso tomados isoladamente, seriam posições filosóficas equivocadas na análise do significado do mundo, com a ressalva de que considerava o materialismo "mais consequente" (Schopenhauer, 2005, p. 77). Partindo do objeto, a busca do materialismo seria apenas pelo primeiro estado da matéria, explicando tudo o mais através de um mero mecanismo, tomando também o conhecer como uma simples modificação da matéria (Materie), como um estado que dela se origina por intermédio da causalidade. Isso, para o filósofo, é legítimo, mas, à afirmação de que o conhecimento é mero acidente da matéria, pode ser, de modo igualmente legítimo, partindo do sujeito, contraposta a afirmação de que a matéria é apenas modificação do conhecimento do sujeito, pelo que se configura um incômodo equilíbrio entre as posições antagônicas (Schopenhauer, 2005); essas duas visões contraditórias, paradoxais, dificilmente 
conciliáveis, formam o que ele chama de uma antinomia em nossa faculdade de conhecimento (Antinomie in unserm Erkenntnisvermögen):

\begin{abstract}
Assim, necessariamente, vemos de um lado a existência do mundo todo (das Dasein der ganzen Welt) dependente do primeiro ser que conhece (abhängig vom ersten erkennenden Wesen ), por mais imperfeito que seja; de outro, vemos esse primeiro animal cognoscente inteiramente dependente de uma longa cadeia de causas (Ursachen) e efeitos (Wirkungen) que o precede, na qual aparece como um membro diminuto. (Ibidem, p. 76.)
\end{abstract}

\title{
2. $\mathrm{O}$ idealismo como contrapeso ao materialismo
}

Nesse segundo tópico, veremos como Schopenhauer estabelece a relação entre o materialismo e o idealismo. Para o filósofo dos "Complementos", "a adesão ao ponto de vista idealista é um necessário contrapeso ao materialismo". Assim, "a controvérsia sobre o real e o ideal pode também ser considerada relativa à existência da matéria" (Schopenhauer , 2014, vol. 1, p. 56.) Para Schopenhauer, “o objeto da disputa concerne à idealidade ou realidade da matéria”. A pergunta que resulta da mencionada oposição é se a matéria existe apenas em nossa representação ou se é independente desta. Neste último caso, "a matéria seria a coisa em si, e aquele que assim a considerasse precisaria consequentemente também ser materialista" (Schopenhauer, 2014, vol. 1, p. 56). Ou seja, seria preciso "fazer da matéria o princípio de esclarecimento de todas as coisas" (Schopenhauer, 2014, vol. 1, p. 56). Por outro lado, o pensamento oposto é o idealista, o qual nega que a matéria possa ser a coisa em si. O filósofo sugere que, entre os modernos, apenas Locke afirma direta e categoricamente a realidade da matéria: "Sua doutrina, sob a mediação de Condillac, conduz ao sensualismo e materialismo dos franceses". Berkeley, como supremo idealista (apenas ele dentre os filósofos modernos teria negado a matéria "positivamente e sem modificações"), e Holbach, como supremo materialista, estariam nos extremos dessas doutrinas (Ibidem, p. 57.)

Porém, algo que aparece fortemente nos "Complementos" é a associação entre matéria e vontade, que subsiste ao fundo das formas e representações possíveis na transitoriedade. A matéria seria, nesse sentido, a manifestação propriamente empírica da vontade, tomada pelo filósofo alemão como um equivalente da coisa em si. Já o corpo seria como que uma "estreita passagem" (Schopenhauer, 2013, p. 149) para a compreensão não apenas do fenômeno físico que subsiste ao fundo dos materiais (Stoffe) 
como matéria (Materie), mas também para a constatação efetiva do outro lado do mundo, a vontade, atribuída não apenas ao orgânico, mas também ao inorgânico. A matéria seria, então, em "Sobre a vontade na natureza", apenas a perceptibilidade das aparições da vontade (Schopenhauer, 2013, p. 139). Segundo Brandão, a partir dos "Complementos" (1844) isso se explicitaria ainda mais. Para este autor, tanto a matéria quanto a realidade empírica possuem "idealidade transcendental” (Brandão, 2008, p. 274.), o que significa, de acordo com o pensamento do filósofo da vontade, que há uma relação declarada e assumidamente paradoxal entre metafísica e ciência, o que, no caso de Sade, não funciona dessa maneira. Também Frauenstädt percebe em Schopenhauer um materialista simultaneamente idealista - ou "um materialista idealista" (Frauenstädt, 1876, p. 145). A posição intermediária de Schopenhauer entre o materialismo e o idealismo é mediada por sua compreensão de Kant, que vai inclusive motivar uma crítica à filosofia insular que pode ser transferida aos materialistas franceses: "Somente em lugares como a Inglaterra, onde o dia da filosofia kantiana ainda não raiou, pode-se pensar em uma origem empírica para o conceito de causalidade" (Schopenhauer, 2013, p. 136).

\section{Matéria e vontade}

Para Schopenhauer, o ponto de vista materialista exige que não exista nada além da matéria (Materie) e das forças a ela inerentes (inwohnenden Kräften), o que torna o real um prodígio incompreensível (unbegreifliches Wunder) ante o qual o investigador empírico se deteria ou do qual partiria. Por outro lado, para o metafísico imanente, a matéria deverá ser compreendida, além disso, como visibilidade de alguma outra coisa que nela é revelada e diante da qual nos postamos, por um momento, com o assombro de um selvagem diante de um espelho:

A nossa própria natureza íntima é a vontade, da qual a matéria é a mera visibilidade. No entanto, nunca a matéria aparece sob outra maneira além da que é visível, por assim dizer, sob o véu da forma e da qualidade, portanto nunca é imediatamente apreendida, mas é sempre apenas adicionada ao pensamento como o que é idêntico em todas as coisas sob todas as variedades de forma e qualidade, como aquilo que é precisamente substancial, propriamente falando, em todas elas. Por esta razão, este é sim mais um princípio metafísico do que meramente físico de explicação das coisas, e, para representar todos os seres brotando a partir disto, é realmente algo equivalente a explicá-los por algo que seja muito misterioso (Schopenhauer, 2014, 1, p. 454). 
"Adicionada ao pensamento" refere-se ao fato de que a matéria como tal é abstrata, não é diretamente perceptível, o que proporciona a marca da relação que se estabelece entre materialismo e idealismo. Fica claro que, para Schopenhauer, não se pode tomar a matéria simplesmente percebida (Stoff), o material, as formas, como uma explicação última da representação que temos do mundo objetivo, porque tal explicação sem o dado a priori contido na noção de Materie ampliaria indevidamente a noção de objeto e, simultaneamente, esconderia a relação do fenômeno com um sujeito que o percebe. Nesse sentido, o absurdo do materialismo consistiria nisso, que ele parte do objetivo, toma algo objetivo como último fundamento de esclarecimento; e este seria a própria Materie, como conceito, in abstracto, apenas como ela é pensada ou aquela já penetrada pela forma, empiricamente dada, portanto, o material (Stoff). É por isso que, para o filósofo, "a física nunca pode ser colocada no trono da metafísica" (Schopenhauer, 2014, 1, p. 456).

Para Schopenhauer, a essência da matéria consiste na ação, ou seja, na causalidade, que, na interpretação kantiana de Schopenhauer, repousa em nosso entendimento, pelo que ela precisaria ser considerada também pelo que nela se manifesta. Se do ponto de vista do objeto a matéria apresenta extensão e corporalidade, que consistem no agir, na causalidade, isto se dá apenas em nossa intuição, como uma forma do nosso entendimento, enquanto a matéria em si mesma seria, paradoxalmente, incorpórea e identificada com a própria vontade:

A matéria é a própria vontade, embora já não em si mesma, mas sim na medida em que é intuída, isto é, na medida em que assume a forma de uma representação objetiva. Assim, o que é objetivamente matéria subjetivamente é vontade. Totalmente de acordo com isso, o nosso corpo [Leib] é apenas a visibilidade [Sichtbarkeit], a objetidade [Objektität] da nossa vontade, e, da mesma maneira, cada corpo físico [Körper] é a objetidade da vontade [Objektität des Willens] em cada um de seus graus. ${ }^{1}$ Assim que a Vontade se apresenta ao conhecimento objetivo, ela entra nas formas intelectuais da intuição, no tempo, no espaço e na causalidade. Mas uma vez se destaca como um objeto material[materielles Objekt] em virtude dessas formas. Podemos imaginar formas sem matéria, mas

\footnotetext{
${ }^{1}$ A noção de gradação é inerente à teoria schopenhaueriana da exposição da vontade no mundo fenomênico. O mundo, os objetos em geral e os organismos são arenas onde os diversos graus da exposição da Vontade se digladiam e, no final, a vitória - o domínio - é privilégio do primeiro ocupante representado pelas forças do mundo inorgânico, sustentáculos e mantenedoras do mundo orgânico, vegetal, animal e finalmente humano. Porém, do ponto de vista da vontade como coisa em si, fora do tempo e do espaço, tal coisa não faz mais sentido, pois é exigida a perene concordância das partes entre si, do orgânico e do inorgânico em uma determinação recíproca. As relações espaço-temporais dizem respeito apenas ao fenômeno que se expõe a cada vez na pluralidade fenomênica.
} 
não importa como seriam as formas porque a matéria, despojada de forma, seria a própria Vontade. A Vontade, no entanto, torna-se objetiva apenas porque entra no modo de intuição de nosso intelecto, portanto somente por meio da adoção da forma. O espaço é a forma de intuição da matéria [Anschauungsform der Materie] porque ele é o simples material [Stoff] da forma, mas é só nesta que a matéria pode aparecer (Schopenhauer, 2014, 1, p. 450).

\section{O materialismo sadiano à luz de Schopenhauer}

A crítica de Schopenhauer ao materialismo, que pode ser estendida a Sade, não se refere propriamente ao materialismo, mas sim à matéria como fundamento. Contrapõe-se ao materialismo como crença (ainda que inconsciente) na matéria como coisa em si. A tese de Schopenhauer é a de que toda estrutura anatômica animal é um análogo da vontade ali exposta que regula o tipo (ou a forma específica) da espécie determinada. No mesmo sentido, disto decorre que aquilo que, no fenômeno ou na representação, é a matéria, é também, intimamente, a vontade. Portanto, tudo o que for válido em condições específicas de experiência e de intuição será válido também para a Vontade em si, o que propicia novamente a imagem no tempo de todas as suas relações e propriedades. Assim, a matéria é o estofo do mundo intuído, como a Vontade é o ser em si de todas as coisas.

Assim, o filósofo deploraria o fato de que Sade aparentemente tome o corpo como coisa em si. Poderíamos conceber que, para ele, o pensamento do filósofo francês não teria penetrado a grande e fecunda doutrina da idealidade do tempo e do espaço como já mencionamos, nem nada do que nela está implícito. Sade, devido à concepção materialista, não poderia compreender que a vontade animal, como coisa em si, está fora do tempo, podendo ser mais originária que o animal em si mesmo. $\mathrm{O}$ mais originário, neste caso, é justaposto ao fenômeno caracterizado no tempo e no espaço, sendo este a sua corporeidade. $\mathrm{O}$ animal determinado seria a expressão fenomênica daquela vontade ali exposta. Sade, pelo contrário, escolhe a ordem espaço-temporal. Para o filósofo da vontade, o erro do materialismo é não ter percebido que o querer-viver pode ser algo que antecede a matéria, que esta é a ação daquele. Isso nos remete à noção de circularidade referente ao caráter insaciável da vontade de viver, pois todo ato exterior não é mais do que um veículo do querer originário cuja essência está fora do tempo, do espaço e da causalidade. Estes surgem apenas secundariamente, como uma forma da representação, que é meramente um fenômeno de nosso entendimento, produto do cérebro animal. Sade, 
de fato, não desconsidera o ímpeto do organismo como um querer-viver, apenas o toma como efeito da matéria, o que Schopenhauer também descarta (Schopenhauer, 2014, 1, p. 477).

A matéria ocupa um lugar central na filosofia de Schopenhauer como elemento articulador tanto de sua metafísica em geral como de sua metafísica da natureza em particular e, por outro lado, mas com o mesmo sentido, será considerada também a articulação entre matéria e biologia, ressaltando o foco schopenhaueriano no sujeito do querer e na constatação do autor de que o querer-viver é originariamente um impulso cego, sem finalidade, ligando-se apenas secundariamente aos objetos de satisfação, pelo que se oferecem ao conhecimento. Nesse sentido, a motivação seria o caráter intrínseco àquela vontade, anterior à experiência, mas dada na experiência através do organismo, enquanto o motivo estaria ligado ao objeto de satisfação da vontade, dado apenas na experiência através dos seus objetos: "O movimento independente originado na vontade pressupõe sempre uma causa: entre os entes dotados de cognição, ela é um motivo" (Schopenhauer, 2013, p. 141). Sem vontade, porém, o movimento é impossível. A causa é a ocasião externa da vontade, que se apresenta como princípio único, livre, infundamentada. Por outro lado, no campo da representação, do visível, daquilo que pode ser fundamentado, a relação entre causalidade e animalidade pode ser explicitada da seguinte maneira, utilizando as palavras do próprio filósofo alemão:

O animal é apenas aquilo cujos movimentos se sucedem não conforme à lei de causalidade (Kausalität), mas apenas conforme a lei de motivação, que é a causalidade atravessada e intermediada pelo conhecer: consequentemente, é animal apenas aquilo que conhece, e o conhecer é o caráter próprio da animalidade (Schopenhauer, 1911, VI, p. 18).

É nesse sentido que pensar um problema filosófico de Sade (a sensibilidade) a partir da filosofia de Schopenhauer pode ser produtivo, já que em ambos o sujeito do querer está ligado às causas apenas de modo secundário e, no entanto, se expressa apenas no contexto dos objetos da experiência possível de acordo com uma ordem causal (que lhe serve de motivo ou, em outras palavras, oferece-lhe objetos). A diferença crucial entre os autores está no ponto de origem da sensibilidade. Para Schopenhauer, provavelmente, Sade seria um caso de alguém que chega a conclusões verdadeiras a partir de premissas falsas, exatamente pela sua posição como materialista radical que ignora a idealidade do mundo e, especialmente, fundamenta o em si do mundo na matéria, enquanto para o 
filósofo alemão, essa identidade do mundo como coisa em si estaria dada na vontade, já que esta é identificada não apenas na animalidade, mas também naquilo que é inorgânico e nas forças naturais. Dessa forma, o materialismo de Sade exigiria como complemento uma explicação das forças inerentes à matéria e, por essa via, deveria chegar à vontade que nelas se expressam, o que, no caso dos organismos animais e do humano em particular, solicitaria uma explicação do querer em geral, da vida, da morte e do desejo em particular como expressões de uma mesma vontade metafísica, o que certamente não ocorre em Sade. Haveria neste uma metafísica inconsciente da matéria, pois a explicação se interrompe nas forças naturais que animam a matéria, mas não há explicação para as próprias forças. Nesse sentido, Sade, famoso pelo modo como tratou a sexualidade (associada à crueldade e à morte), aborda esse fenômeno específico da animalidade apenas no contexto desse materialismo do qual é tributário.

\section{Prazer e sexualidade em Sade}

Segundo Monzani, em "Desejo e prazer na idade moderna", a trilha para a compreensão das características do desejo e do prazer para os materialistas nos levaria a considerar Hobbes, La Mettrie e Holbach como precursores de Sade (Monzani, 2011, p. 104). A análise do prazer, da alegria e dos estados de felicidade aponta, nesses autores do materialismo moderno, dentre os quais podemos incluir também Helvétius, para os problemas da diversidade dos caracteres humanos (opinião compartilhada também por Schopenhauer) e do relativismo moral (criticado por Schopenhauer). Especialmente a estratégia libertina de mesclar o sexo com filosofia, apesar de causar certo estranhamento para o leitor moderno, fazia perfeito sentido em meados do século XVIII, pois mostrava que o conhecimento do corpo e de seus instintos "poderia abrir caminho para a linha mais radical do Iluminismo" (Darnton, 1991, p. 26), cujos autores principais são citados acima. No contexto dos libertinos, especialmente em Sade, o prazer é um objeto de reflexão filosófica. Nele, o sentimento amoroso não possui nenhum papel fundamental, dada a excisão do sujeito no processo da sexualidade e sua objetalização como meio para libertação intelectual. Segundo Castro, os afetos são reduzidos "a processos mecânicos, as sensações percorrem a superfície da epiderme como um estímulo nervoso até chegarem ao cérebro" (Castro, 2006, p.169), onde são registradas e se acumulam, tendo como efeito suplementar deste processo a 
expansão da consciência através da experiência ampliada e radicalizada ${ }^{2}$. Ressalte-se aqui a ênfase no outro como mero objeto e, com isso, do ponto de vista moral, a possibilidade de ignorar todos os pruridos relacionados ao prazer individual, às convenções sociais, aos dogmas religiosos e, também, em termos filosóficos, à possibilidade de se construir um pensamento vinculado à prática sexual transgressora, compreendida como um meio de aprimoramento no contexto da natureza e da própria individualidade. O controle dos próprios sentidos, portanto, dos instintos, é sinal de potência, enquanto a entrega é sinal de fraqueza. Assim, a fantasia, a dissimulação e a teatralização parecem ter também uma função no processo, pois implicam em potencialização sexual e um suplemento de prazer que só pode ser acrescentado pelo desregramento de todos os sentidos através do poder de um e da transformação do outro (ou outros) em objeto.

Em Sade - ou a individualidade desejante -, Monzani evoca La Mettrie a respeito da ênfase na valorização da sensação de prazer de modo independente de sua causa específica (Monzani, 2013, p. 46). Para Monzani, é como se La Mettrie abrisse a porta para noção sadiana de fantasia, ao permitir acesso para o que quer que venha a produzir os estados de prazer associados à felicidade, não importando a sua origem ou finalidade. Com Sade, de modo bem mais específico, o sujeito empírico é suporte das fantasias projetadas sobre o objeto sensível (Monzani, 2013, p. 46). Portanto, a ilusão, para Sade, empresta valor aos objetos (Monzani, 2013, p. 47). A intensificação do prazer a partir da fantasia parece conduzir aos mundos bizarros do universo sadiano. Porém, segundo Bocca (2016), em Sade não se trata de um "polimento dos prazeres", mas especificamente de uma intensificação dos sentidos mediante os recursos imaginativos. Ainda de acordo com esse autor, trata-se "da multiplicação indiferenciada e o acúmulo das sensações prazerosas" (Bocca, 2016, p. 125). O excesso seria essa via sadiana de ruptura com as travas e freios impostos no contexto social à própria fantasia. Dessa maneira, a abertura para o gozo improvável também possibilitaria a intensificação dos sentidos e a

\footnotetext{
${ }^{2}$ Há nessa concepção que objetaliza o sujeito algo que pode ser interpretado como um processo psicológico ativo e talvez benéfico (não fosse o seu caráter mortífero), no sentido da superação das resistências psíquicas, pois as defesas e condicionamentos dos impulsos do eu são vencidos pela violência e pela orgia, posto que a sua orquestração elimina qualquer possibilidade de preferência ou mesmo de recuo frente à dor e à ruptura das categorias morais às quais o sujeito está vinculado. Nesse sentido, pensando nos indivíduos moralistas e hipócritas do tempo de Sade (idênticos, aliás, aos atuais), a sua filosofia tem também um forte caráter político, uma política do corpo visando a liberação da inteligência, que é reprimida junto com a sexualidade. $\mathrm{O}$ aspecto destrutivo, a radicalização pulsional mortífera, no entanto, metaforiza a destrutividade da própria natureza e a tendência à entropia inerente a tudo o que é físico. É como um experimento de exasperação das forças e finalmente o seu resfriamento, ademais, inevitável, ainda que se tratasse de amor apaixonado. Lembremo-nos de Freud e seu texto sobre a tendência universal à depreciação na esfera amorosa.
} 
proliferação de prazeres impensados. Porém, para Castro (2006), há uma nuance curiosa quanto aos objetivos propriamente filosóficos do teatro da crueldade sadiano; o prazer físico em Sade "pode ser uma ferramenta e até mesmo uma consequência, mas o prazer intelectual será sempre o maior objetivo do libertino sadiano" (Castro, 2006, p. 165). Para a autora, é através do filosofar que o libertino atinge a ascese. Poderíamos perguntar se não haveria um perfume curiosamente platônico em tudo isso (refiro-me ao discurso de Sócrates relatando o que aprendeu sobre o amor com Diotima), a julgar pelo que nos diz essa autora. Só que não seria mais algo relacionado ao amor e à edificação de um pensamento baseado em um ideal de verdade conectado à moral, mas à simplificação das relações e à destruição de toda e qualquer base moral unívoca que, na estrutura social na qual vive o autor, estaria ligada, como em Nietzsche, ao cristianismo. A libertação da potência humana através da orgia e da experiência radical, porém ordenada, dos prazeres do corpo seria esse contraveneno.

Tudo isso guarda relação direta com o materialismo do autor e com seu anticlericalismo. Para Sade, não existe a consideração do problema mencionado por nós anteriormente no contexto schopenhaueriano, a saber, a incompletude do materialismo. Para ele, são consideradas apenas as hipóteses do próprio materialismo em oposição ao criacionismo, a saber, se a matéria seria ou em si mesma inerte, pelo que necessariamente precisaria ser animada por um Deus, ou se ela seria, como ele mesmo concebe, em si mesma ativa. Nesse sentido, de fato, não é considerada a doutrina transcendental kantiana e as suas possíveis consequências para o materialismo, como ocorre em Schopenhauer, especialmente a pergunta pelo domínio do pensamento sobre o ser enquanto ser representado, ainda que restrito aos objetos da experiência, ou sobre o que restaria além dessa possibilidade de representação, no sentido que pode ser considerado a partir de uma analítica do entendimento puro (Kant, B 303). Também, do mesmo modo, a hipotética consideração de uma Wille zum Leben ou algo semelhante, levada a cabo por Schopenhauer a partir da sua recepção da herança kantiana, também não existe no filósofo francês. A posição de Sade pode ser bem compreendida (e nesse sentido em completo acordo com a metafísica da natureza de Schopenhauer) no "Diálogo entre um padre e um moribundo" (Sade, 2001, p. 23), quando escreve que: "os efeitos naturais devem ter causas naturais sem que seja necessário supô-las sobrenaturais" (Sade apud Bocca, 2016, p. 125). De um ponto de vista epistemológico, disso decorre, como vemos em Bocca (2014), que Sade, influenciado por pensadores como La Mettrie e Condillac, subverte a articulação clássica entre razão e sensibilidade: "donnant à la raison une fonction inverse, 
voire contraire. La raison reste alors soumis et dépendante de la sensibilitê" (Bocca, 2014, p. 65). Essa inversão entre sensibilidade e razão, tornando a razão tributária ou dependente da sensibilidade, também aparece em Schopenhauer. Porém, a questão tal como aparece na argumentação do filósofo delimita um campo específico de interesse, o anticlericalismo: "Prova-me a inercia da matéria e admito o criador. Prova-me que a natureza não basta a si mesma, e te permito conceber-lhe um senhor" (Sade, 2001, p. 21). Castro não menciona o anticlericalismo, mas opõe Sade aos filósofos iluministas, como um maldito: "Sade construiu a sua teoria como uma consequência das contradições da moral iluminista" (Castro, 2006, p. 197). A autora segue dizendo que "Sade, então, fez aos iluministas aquilo que, numa menor escala, o moribundo fez ao padre, em Dialogue entre un Prêtre et un Moribond" (Castro, 2006, p. 197). Dessa forma, evocando nosso moribundo, ocorre a refutação de otimistas e edificantes valores iluministas aos quais o filósofo opõe sua radicalização do que considera ser a verdadeira doutrina da natureza, a destruição. As teses iluministas, bem como o cristianismo, não passariam de simples erros aos quais ele oporia um combate sem tréguas através de seus próprios argumentos.

\section{A matéria não é inerte}

Em termos schopenhauerianos, não há nada de propriamente equivocado na concepção de que a matéria não é inerte. Apenas ocorre que os estados da matéria sejam apenas as formas específicas de perceptibilidade da vontade metafísica na pluralidade fenomênica. A fantasia ou imaginação sadiana aparece em Schopenhauer como ilusões e ardis que impulsionam o apetite insaciável do querer-viver. Sade poderia talvez ser compreendido, no sentido schopenhaueriano, como um mestre da afirmação unilateral e despudorada do querer-viver, pelo que poderia ser utilizado para descrever a afirmação da vontade, mas também a sua exaustão, de um modo que Schopenhauer jamais concebeu. Se o valor da vida é que ela ensine a não querer (Schopenhauer, 1991), Sade parece estar de algum modo de acordo com isso, pois não é da potência do desejo que ele se vale, mas sim da sua superação e dominação por uma potência destrutiva e criminosa, no sentido em que esta potência destrutiva se afirmaria plenamente na consumação do ato sexual, o qual não é espontâneo, amoroso, mas um teatro no qual se devolveria ao indivíduo toda a sua potência e liberdade para exercer a sua perversidade natural de modo tão pleno quanto possível. Isso, de acordo com Schopenhauer, seria apenas a exacerbação daquilo que já se observa em geral, pois, para ele, o ser humano é o mais perverso dos seres 
naturais e a maldade é um componente em maior ou menor grau de seu caráter, bem como o egoísmo e a compaixão. É da composição desses três afetos fundamentais que resultam as nossas características individuais. No mesmo sentido, o sofrimento no mundo biológico do qual participamos é resultado da afirmação do querer-viver, que é obrigado a devorar a sua própria carne e deve ser considerado também a partir da identidade metafísica fundamental entre o atormentador e o atormentado. Sade, de fato, apresenta uma flagrante disposição para aceitar incondicionalmente todas as consequências de tal existência afirmativa, levando-a ao extremo da perversidade; mas, Schopenhauer diria, com essa atitude tanto a dor quanto o sofrimento são igualmente afirmados e, em certo sentido, amplificados (Schopenhauer, 1991, p. 233). A diferença entre os autores se dá tanto no sentido da compreensão íntima da natureza, pois há, em Schopenhauer algo que antecede o sensorial e o material, quanto do ponto de vista do significado moral do mundo. Se a vontade se expõe e se afirma na pluralidade, a identidade íntima de todos os seres como expressões de um mesmo ímpeto cego gera o sofrimento e se explicita nos afetos egoísticos e cruéis, justificando também, de acordo com a compreensão de Schopenhauer, a defesa da compaixão como fundamento da moral. O mundo de Sade e Schopenhauer é basicamente o mesmo, mas ambos oferecem pontos de partida diferentes para as suas explicações (vontade e matéria) e chegam a conclusões diferentes, de um ponto de vista moral, posto que a intensificação sadiana afirma o querer-viver e a destrutividade, o que Schopenhauer também reconhece, mas não elogia.

\section{Atividade e entropia}

Se o problema do materialismo na comparação entre os dois autores apresenta essa pequena inflexão na relação teórica com as forças que animam a matéria, que em Schopenhauer se tornaria mais tarde um problema de proporções gigantescas, a saber, a sua essência como uma vontade cósmica e inerente à matéria, que, nos "Complementos", é a própria vontade (embora não em si mesma, mas na medida em que é intuída), não poderíamos dizer que eles diferem tanto assim no que concerne à necessidade de considerar o mundo a partir do próprio mundo sem a admissão de nenhuma força criadora autônoma, sem nenhum demiurgo. Em Schopenhauer, isso se dá porque a vontade só atinge o conhecimento em seu último grau de exposição, o animal em geral e o humano em particular, que apresenta não apenas o conhecimento intuitivo, mas a ele acrescenta o 
conceitual. Em Sade, naturalmente, isto se dá porque a matéria é o próprio princípio ordenador de todas as outras relações.

Mas, do ponto de vista da causalidade, isto é, da correlação entre as forças e da ação em geral, em que isso implica? Disso decorre, necessariamente, que a destrutividade é inerente a este mundo, pois, na ausência de uma força ordenadora externa, há um embate entre as forças originariamente cegas que o constituem. Não há paradeiro para o desgaste das forças que se renovam na existência. A diferença entre eles se dá na historicidade de Sade e no Nunc Stans de Schopenhauer. Para este filósofo, a degradação e a entropia são relações verdadeiras, mas mesmo que o mundo e o universo inteiro caminhem para o esgotamento final de todas as suas relações e das forças envolvidas no processo da existência física, a vontade metafísica, em um sentido lógico anterior ao que é visível na representação, não depende da causalidade, antes a causalidade é que depende dela. Assim, o ciclo da existência é apenas perene, não eterno, mas a vontade, que possibilitou a existência como um simples impulso cego, está fora do tempo e do espaço. Para Schopenhauer, portanto, o excessivo apego à historicidade conduziria ao erro de reduzir a vontade à sua visibilidade, à causalidade, enquanto a causalidade seria, como foi dito acima, expressão visível da vontade livre (a liberdade está no ser e não no agir, pois este último é visto como aquilo que é regido pelo princípio de razão em todas as suas formas).

Olhando essas relações de modo inverso, o eterno retorno do querer-viver tem como contrapartida a certeza da morte do organismo individual, pois o organismo físico participa das relações inerentes à visibilidade da matéria, o que nos conduz inexoravelmente ao desgaste, à corrupção e à morte. Nesse sentido, o universo inteiro pode rumar continuamente para a entropia, em uma escala de tempo quase infinita, mas, mediante a proposição de que a vontade que anima toda a atividade é em si mesma incorruptível e imperecível, todo o ciclo entre atividade e entropia pode se renovar eternamente. Imagina-se que Sade, diante disso, concordaria com a proposição de que o mal é inerente ao entrechoque de forças e que o egoísmo e a crueldade também seriam decorrências do que é inerente ao mundo. Entretanto, provavelmente denunciaria uma tendência dogmática no conceito de vontade schopenhaueriano, posto que ela pode ser compreendida (especialmente a partir dos Ergänzungen) apenas como a própria matéria tomada in abstracto e como o "ser em si de todas as coisas" (Schopenhauer, 2014, 1, p. 450). O fenômeno ou objetivação da vontade seria, para Sade, a imagem da totalidade do possível e qualquer coisa que rumasse para além dessa fronteira discernível seria considerada mera suposição, dogma religioso ou filosófico. Inversamente, para 
Schopenhauer, tomar a matéria como princípio também seria, de certa forma, um cul-de$s a c$, uma metafísica inconsciente, também um artigo de fé, pois, para ele, a matéria em si mesma, despojada de todas as suas formas e qualidades, seria sem extensão, sem espacialidade e, portanto, incorpórea (Schopenhauer, 2014, 1, p. 451)

\section{Virtude e transgressão}

Se ambos os autores concordam que a existência abriga o mal em seu íntimo e têm este como condição inerente e radical, Sade, diferentemente de Schopenhauer, estabelece uma narrativa da transgressão na qual a afirmação do mal radical aparece em expressões tais como: "É uma verdade irrefutável que a prosperidade pode acompanhar o crime" (Sade, 2008a, p. 29).

De um ponto de vista político, parece ser possível encarar a defesa da transgressão sadiana como uma explicitação da transgressão comum que tenta se ocultar sob os véus da hipocrisia no íntimo da sociedade humana. Ela aparece como dissimulação da sexualidade e tem como um de seus efeitos o surgimento da literatura pornográfica, muitas vezes conhecida no Brasil com o nome cômico de "catecismos". Nesse sentido, a busca do prazer, que promove a alegria, está relegada, especialmente no que concerne às mulheres e aos adolescentes, ao mundo da transgressão. As mulheres, especialmente, precisam ocultar seu prazer. Em "Justine", livro que trata jocosamente dos "infortúnios da virtude", vemos Sade caracterizar os tipos humanos de Justine e de Juliette, sua irmã. Nessa oposição, se explicita a denúncia de que o funcionamento da sociedade é algo adverso à virtude e que, dessa forma, estimula o vício encoberto pela hipocrisia estampada na figura de Juliette. Sade as caracteriza com precisão, expondo os efeitos mundanos dos caracteres das irmãs. O que as opõe não é tanto a anteposição entre bem e mal, mas entre virtude e vício. Porém, justamente devido a essa posição prática de sua filosofia, já existe nessa linguagem o conjunto de oposições presentes no universo religioso. Isso é importante pontuar, pois, Sade, assim como Schopenhauer, apesar de professar posições muito diferentes e muitas vezes até opostas às dos sistemas religiosos de metafísica, permanece atado à sua forma de linguagem, dialoga com eles a partir dela, de certa forma depende deles para ser compreendido e isso é, certamente, uma questão de caráter sociológico e político. No contexto de Justine e de sua irmã, o vício, apesar de ser tão espontâneo e natural quanto a virtude, leva uma vantagem sobre ela do ponto de vista social, pois, através da dissimulação, o caráter vicioso alcança uma certa imunidade para 
exercer suas ações malignas, já que, como escreveu La Rochefoucauld (2014, p. 27), "costumamos fazer o bem, para poder fazer impunemente o mal". A discussão de Sade difere da de Schopenhauer em um ponto fundamental, pois, para o primeiro, o corpo e suas sensações são o ponto de origem; ele faz, por assim dizer, uma metafísica da matéria ${ }^{3}$. Para Schopenhauer, o corpo é ponto de passagem entre o físico e o metafísico, que é a vontade, sendo que a virtude não é ensinada, pois não é frutífero tentar fazer isso. Ensinar a virtude seria mera pretensão, "seria tão tolo esperar que os nossos sistemas morais e éticos criassem caracteres virtuosos, nobres e santos, quanto que nossas estéticas produzissem poetas, artistas plásticos e músicos" (Schopenhauer, 2005, p. 353), pelo que o conceito de ensino possui uma função apenas suplementar, instrumental. Nesse sentido, seria duvidoso pensar em uma educação libertina, a não ser no sentido da revelação de caracteres pré-existentes, encobertos pelo verniz social.

\section{A perversidade do espírito}

Se o mal radical é algo inerente ao mundo, intrínseco a ele e também ao caráter e às relações humanas, há um contraste entre o mundo natural e o fenômeno moral, entre a inteligência que ilumina o caráter da animalidade em oposição à indiferença cósmica inerente aos fenômenos que constituem o mundo em si mesmo. Dessa forma, para Schopenhauer, o significado do mundo não é apenas físico: "O pensamento de que o mundo possua apenas uma significação física e não moral, constitui o mais grave engano, originado pela pior perversidade do espírito" (Schopenhauer, 1991, p. 187). Schopenhauer insiste em que exista um significado moral do mundo, mas este é dado justamente a partir da constatação acerca da autodevoração do querer viver multiplicado exponencialmente na infinidade dos seres naturais, dos quais a humanidade se destaca apenas pelo uso de conceitos e não por uma diferença intrínseca proporcionada de qualquer outra forma. $\mathrm{O}$ mundo, para ele, é identificado, em sentido figurado, com o “demônio" (Schopenhauer, 1991, p. 186.). Nesse sentido, a ordem moral é apenas algo

\footnotetext{
${ }^{3} \mathrm{Em}$ "O mundo materialista da pornografia", Margareth C. Jacob escreve o seguinte: "Por volta de 1700, o materialismo tornou-se a metafísica preferida, mas não a única, da literatura que procurava estimular, com seus textos, a excitação e os desejos" (Jacob, 1999, p. 170). De fato, as narrativas eróticas rapidamente abraçaram o materialismo mecanicista. "Esse novo recurso metafórico e metafísico" proporcionou uma narrativa, um recurso à fantasia para expor a experiência do mundo urbano entre meados e fim do século XVII, universo social que permitiu a articulação de uma nova metafísica da natureza e de uma nova forma narrativa. "O atomismo e o materialismo possuem numerosas e diferentes origens sociais e filosóficas, e entre suas raízes sociais estaria o indômito mundo que produziu e consumiu a pornografia moderna" (Jacob, 1999, p. 171).
} 
imposto unilateralmente pelo julgamento da existência que aparece, iluminada pelo conhecimento, como algo essencialmente perverso, errôneo e que não deveria existir, sendo preferível a paz do nada, a não-existência, o que é diferente de uma opção pelo suicídio ou de uma busca consciente pelo esgotamento dessa experiência, como vemos em "120 dias de Sodoma”. Por isso mesmo, todo vivente seria digno de compaixão e mais ainda a Humanidade iluminada pela autoconsciência.

É por este viés que o olhar para a obra de Sade nos impõe ao menos dois aspectos relevantes. O primeiro é a constatação já mencionada de que todo aquele teatro sexual da crueldade, todas aquelas ações visando o esgotamento, a entropia, apenas reproduzem ou expressam de modo mais nítido o próprio movimento inerente à natureza, despindo a humanidade de seus véus imaginários ligados aos dogmas e conceitos religiosos estabelecidos nas diferentes culturas, especialmente na cristã, sendo uma explicitação da perversidade natural e humana. O segundo é o de que a própria busca de afirmação do querer e as formas de dominação que explicitam a mecanicidade e a causalidade dos fenômenos naturais em seu grau extremo são ainda formas de afirmação da vontade autodevorante na experiência, pelo que foram negadas teoricamente pelo metafísico da vontade, embora isso não queira dizer que deveriam ser impedidas de acontecer em termos práticos, pois, na verdade, tanto faz, já que não há qualquer finalidade e também não há um julgamento final da existência a partir de uma ordem moral. Para Schopenhauer, é indiferente que a vontade se explicite desta ou daquela forma, já que isso apenas expressa o ímpeto cego que lhe caracteriza e a ausência de finalidade como pano de fundo de toda finalidade possível. O verdadeiro aspecto moral envolvido se refere ao sofrimento intrínseco à existência, à inutilidade de todos os esforços, o cansaço que todo esse circuito sem finalidade expressa. Assim, pode ser considerado verdadeiramente um curto-circuito que, persistindo através da reprodução, tem a chance de alcançar a negação (um problema schopenhaueriano que foge ao escopo deste artigo).

De fato, visto dessa maneira, Sade pode ser compreendido, do ponto de vista de Schopenhauer, não como um autor que estaria propriamente explorando as possibilidades do prazer no que diz respeito aos seus alvos, mas como aquele que busca pulverizar o próprio sentido do prazer como busca sensual, revelando no fundo de toda a parafernália da existência o seu caráter essencialmente mecânico, incontido, repetitivo, entrópico, mortífero. A questão que resta desse testemunho da natureza essencialmente maléfica do mundo poderia ser formulada de um ponto de vista schopenhaueriano da seguinte maneira: se, para Schopenhauer, no fundo de toda causa há algo que não pode ser 
fundamentado e se no fundo do conhecer há algo que quer o que não sabe, o que estaria, para Sade, no fundo da atividade que busca a afirmação da própria existência de modo geral e do prazer de modo particular? A simples destruição. Essa reflexão considera as cenas de "120 de Sodoma” (2008b), por exemplo, nas quais há um rígido controle das circunstâncias, um circuito fechado, uma mônada que exaure a si mesma como que em um grande e mortífero teatro destrutivo e autodestrutivo, no qual prepondera o desprezo pela vida e pela sua conservação. Se em Schopenhauer o mal é a essência do mundo e, portanto, inevitável, em Sade o mal é desejável, na medida em que liberta o homem. Em Schopenhauer, não escaparíamos da análise dos caracteres fundamentais feita em "Sobre o fundamento da moral", bem como os diversos momentos em que caracteriza o egoísmo natural ("mais animal") e a malignidade humana (“mais diabólica”): “O egoísmo pode levar a todas as formas de crimes e delitos, mas os prejuízos e as dores causados a outrem são para si um mero meio e não um fim, aí entrando de modo apenas acidental" (Schopenhauer, 1995, p. 119). Por outro lado, escreve ele, "para a maldade e a crueldade o sofrimento e a dor de outrem são fins em si; alcança-los, o que dá prazer" (Schopenhauer, 1995, p. 119).

\section{Destruição ou negação do mundo}

Se colocamos lado a lado Sade e Schopenhauer, reencontramos a nossa própria humanidade naquilo que tem de fundamental: somos movidos (ou "agidos") por forças naturais inerentes e que constituem nossas qualidades tal como existem efetivamente. $\mathrm{E}$ nenhuma força pode aparecer sem um substrato material. Em Schopenhauer, bem como em Sade, o egoísmo e a maldade são características profundamente enraizadas em nossa natureza, sendo, portanto, constituintes também da sociedade em que vivemos. Porém, em Sade, todo excesso é bem-vindo, pois ele nos intensifica e nos torna mais potentes, livrando-nos da fraqueza que sucumbe diante das outras forças que se impõem no mundo natural. A hipocrisia é uma casca e um verniz necessário à vida social, pois sem a falsificação das moedas do espírito não haveria civilização. Schopenhauer concorda com isso, pois a visão direta do mal impõe um problema difícil de resolver e que impeliu a Humanidade, em toda parte, a tomar como ajuda a maquinaria de um outro mundo que subsiste através de conceitos e de doutrinas que apelam para deuses e mandamentos supostamente transmitidos aos homens para regular o seu comportamento através de recompensas e ameaças (Schopenhauer, 1995, p. 121.). O efeito civilizatório se dá 
justamente no ocultamento de características reais, substituídas por comportamentos mais adequados ao bom funcionamento da sociedade, portanto assimiláveis, tomados, em geral, apenas de modo aparente, já que os impulsos que nos comandam intimamente não são evidentes, além de que nossas características maléficas superam o que há de pior na natureza simplesmente animal.

Ambos os autores denunciam a hipocrisia inerente às relações sociais. Sade, mais radical, explora o materialismo em suas consequências mais extremas, chegando a considerar desejável a afirmação do mal inerente à nossa natureza, pelo que a hipocrisia é conveniente. Por isso, sob a pena de Sade, Justine, a virtuosa, sofre e tem que sofrer, enquanto Juliette explora as aparências para fazer prevalecer e potencializar a sua essência, sendo que a dissimulação é considerada uma importante característica auxiliar para a afirmação do libertino nesse mundo humano o qual não admite a sua própria natureza maléfica. Nesse sentido, o libertino atua de modo estratégico, evitando a repressão enquanto se libera do recalque imposto ao eu pelo processo civilizatório. Se cotizamos os dois autores, vemos que se assemelham na caracterização do mundo humano como um fenômeno natural, embora Schopenhauer insista que há um impulso cego, a vontade, que é o ser em si de todo acontecer material (a matéria como visibilidade da vontade). Se ambos reconhecem a espontaneidade do mal, do egoísmo e da compaixão, Schopenhauer atribui valor superior a este último afeto, enquanto Sade o deplora, considerando-o sinal de enfraquecimento de nossa potência afirmativa e legitimamente destruidora, como o seria a própria natureza.

\section{Referências bibliográficas}

Bocca, F.V. [2014]. Le Marquis de Sade: un matérialisme aux consequénces ultimes. Revista Natureza Humana, 2014, 16(1).

Bocca, F.V. [2016]. Do Estado à Orgia - Ensaio sobre o fim do mundo. Hobbes, Locke, Condillac, La Mettrie, Sade. Curitiba: CRV, 2016.

Bocca, F.V.; Araujo, A. (Org). [2013]. La Mettrie ou A filosofia marginal do século XVIII. Curitiba: Ed. CRV, 2013.

Brandão, E. [2008]. A concepção de matéria na obra de Schopenhauer. São Paulo: Humanitas, 2008.

Darnton, R. [1991]. Edition et sédition: L'Univers de le littérature clandestine au XVIIIe siècle. Paris: Gallimard, 1991. 
Frauenstadt, J. [1876]. Neue Briefe über die Schopenhauersche Philosophie. Leipzig: Brockhaus, 1876.

Jacob, M. [1999]. O mundo materialista da pornografia. In: Hunt, L. (Org.) A invenção da pornografia: Obscenidades e as origens da modernidade. 1500-1800. Traduzido por Szlak, C. $1^{\circ}$ ed. São Paulo: Editora Hedra, 1999.

Kant, I. [2016]. Crítica da Razão Pura. Traduzido por Mattos, F.C. Petrópolis: Ed. Vozes, 2016.

La Rochefoucauld, F. [2014]. Reflexões ou Sentenças e máximas morais. São Paulo: Penguin Classics Companhia das Letras, 2014.

Monzani, L.R. [2011]. Desejo e prazer na Idade Moderna. Curitiba: Champagnat, 2011.

Monzani, L.R. [2013]. Sade - ou a individualidade desejante. In: Bocca, F.V.; Araujo, A. (Org.). La Mettrie ou A filosofia marginal do século XVIII. Curitiba: Ed. CRV, 2013.

Sade, M. [1966]. Ouvres Completes. Paris: Au cercle du livre précieux, 1966.

Sade, M. [2008a]. Os infortúnios da virtude. Trad. Celso Mauro Paciornik. São Paulo: Iluminuras, 2008a.

Sade, M. [2008b]. Os 120 dias de Sodoma. São Paulo: Iluminuras, 2008 b.

Schopenhauer, A. [1911]. Arthur Schopenhauer Sämtliche Werke. Editado por München, P.D.; Piper, R. e Co. $10 \mathrm{v}^{4}$.

Schopenhauer, A. [2005]. O mundo como vontade e como representação. Traduzido por Barboza, J. São Paulo: UNESP, 2005.

Schopenhauer, A. [2012]. O mundo como vontade e representação: Complementos. Traduzido por Fonseca, E.R. Curitiba: UFPR, 2012.

Schopenhauer, A. [2013]. Sobre a vontade na natureza. Traduzido por Silva, G.V. Porto Alegre: L\&PM, 2013.

Schopenhauer, A. [1991]. Parerga e Parlipomena. In: Schopenhauer. Coleção: Os Pensadores. Traduzido por Cacciola, M.L. São Paulo: Nova Cultural, 1991.

Schopenhauer, A. [1995]. Sobre o fundamento da moral. Traduzido por Cacciola, M.L. São Paulo: Martins Fontes, 1995.

\footnotetext{
${ }^{4} \mathrm{O}$ número romano associado à citação indica o volume específico ao qual se refere.
} 